\title{
Indocyanine Green Angiography in Salvage Planning: From Pedicled Supraclavicular Flap to Free Supraclavicular Flap
}

\author{
Hemin Sheriff, MD, PhD ${ }^{1 *}$; Carmen Vega Garcia, MD, PhD²; Jacinto Garcia Lorenzo, MD, PhD; \\ Susana Lopez Fernandez, MD, PhD4; Shokha Shahab Kareem, MD; Christopher Hankins, MD, PhD; \\ Jaume Masia, MD, PhD; Manuel Fernandez Garrido, MD, PhD²
}

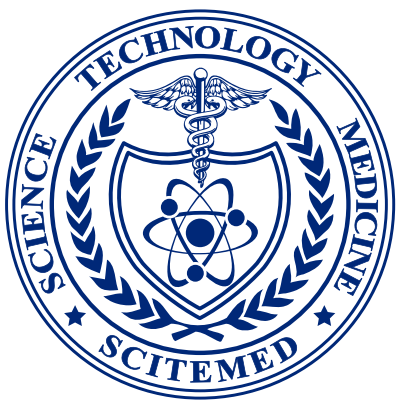

${ }^{1}$ Department of Surgery, College of Medicine, University of Sulaimani, Sulaymaniyah, Iraq 2 Department of Plastic Surgery, Hospital de Sant Pau i de la Santa Creu, Barcelona, Spain ${ }^{3}$ Department of Otorhinolaryngology, Hospital de Sant Pau i de la Santa Creu, Barcelona, Spain ${ }^{4}$ Department of Plastic Surgery, Hospital de Sant Pau i de la Santa Creu, Barcelona, Spain ${ }^{5}$ Department of Plastic Surgery and Burns, Sulaymaniyah Teaching Hospital, Sulaymaniyah, Iraq

${ }^{6}$ Premier Plastic Surgery, Texas, USA

\begin{abstract}
The supraclavicular flap has gained popularity in recent years as a reliable and easily harvested flap with occasional anatomical variations in the course of the pedicle. In this case study, the excision of a cancer lesion on the face of 70-year-old female patient had resulted in a soft tissue defect of size $8 \times 9$ $\mathrm{cm}$. The reconstruction of the surgical defect was done by using the supraclavicular perforator flap. The flap perforators were marked preoperatively with a handheld Doppler using indocyanine green angiography. During the flap dissection, the dominant perforator was determined by a selective clamping of each of the perforators guided by the indocyanine green angiography. Though the distal perforator was determined to be the dominant one, the pedicled flap design was found to be of inadequate length to reach the surgical defect. Consequently, the flap was turned into a free flap. The pedicle was anastomosed to the branches of facial vessels and survived completely. In conclusion, we believe that the dominant perforator may be identified by intraoperative indocyanine green angiography which would help in making a proper decision for flap design.
\end{abstract}

\section{INTRODUCTION}

The supraclavicular flap has gained popularity in recent years as a reliable and easily harvested flap which is ideal for head and neck reconstruction [1]. Due to its tissue specificity, the supraclavicular flap provides an alternative to other free flaps in the reconstruction of defects of the head and neck $[2,3]$.

In 1903, Toldt, an anatomist, first illustrated and named the arteria cervicalis superficialis. The artery originates from the thyrocervical trunk, exiting between the trapezius and sternocleidomastoid muscles $[1,4]$. Kazanjian and Converse are credited with the first clinical application of this flap in 1949 [5-7]. The use of this flap had gone out of favor until the early 1990s. It was then that Norbert Pallua rediscovered the supraclavicular flap and popularized its use. Pallua et al. had used this flap for post burn neck contracture, as well as head and neck malignancies [8-12].

The supraclavicular flap is usually raised as a pedicled island or as a transposition flap. The donor site may either be closed directly or with a split skin graft, depending on the size of the flap, laxity of the skin of the supraclavicular and shoulder region, and the pre-expansion condition of the flap. The use of supraclavicular flap as a free flap was reported by Pallua, who used this flap as a free flap for hand and foot reconstruction in two patients [12]. It was also reported as a free flap for head reconstruction by Cordova et al. and Alves et al. [13,14].

The pedicle of this flap emerges from transverse cervical artery and is located in the triangle formed by the dorsal edge of the sternocleidomastoid muscle, the external jugular vein, and the medial part of the clavicle $[5,15,16]$. Anatomical variations have been described in the pathway of the dominant pedicle to the flap, which courses under the clavicle and turns upwards towards the skin. Due to the variations in the course of the pedicle, the length of the pedicled flap is variable.

The aim of this case report is to show (1) that the determination of the dominant pedicle may be aided with the use of indocyanine green angiography and (2) that the supraclavicular flap can be converted to a free flap if the dominant pedicle is unfavorable to a pedicled flap design.

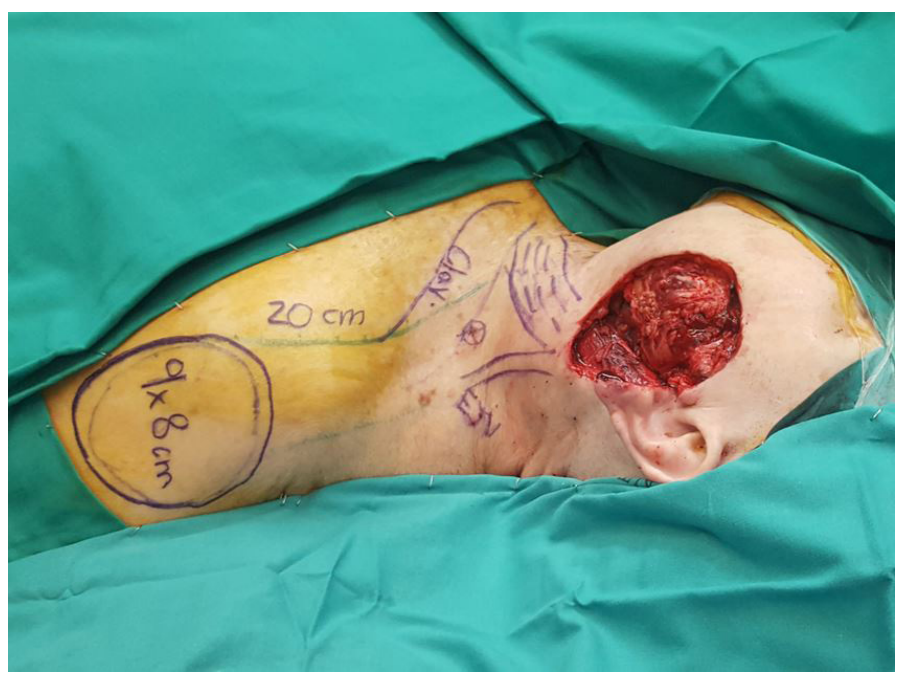

Figure 1. Wide resection of the tumor resulted in a large soft tissue defect of the size of 8 $x 9 \mathrm{~cm}$. A left supraclavicular perforator flap was planned. The flap borders were marked having a length of $20 \mathrm{~cm}$ from the pedicle and width of $9 \mathrm{~cm}$ at the distal part to match the size of the defect. 


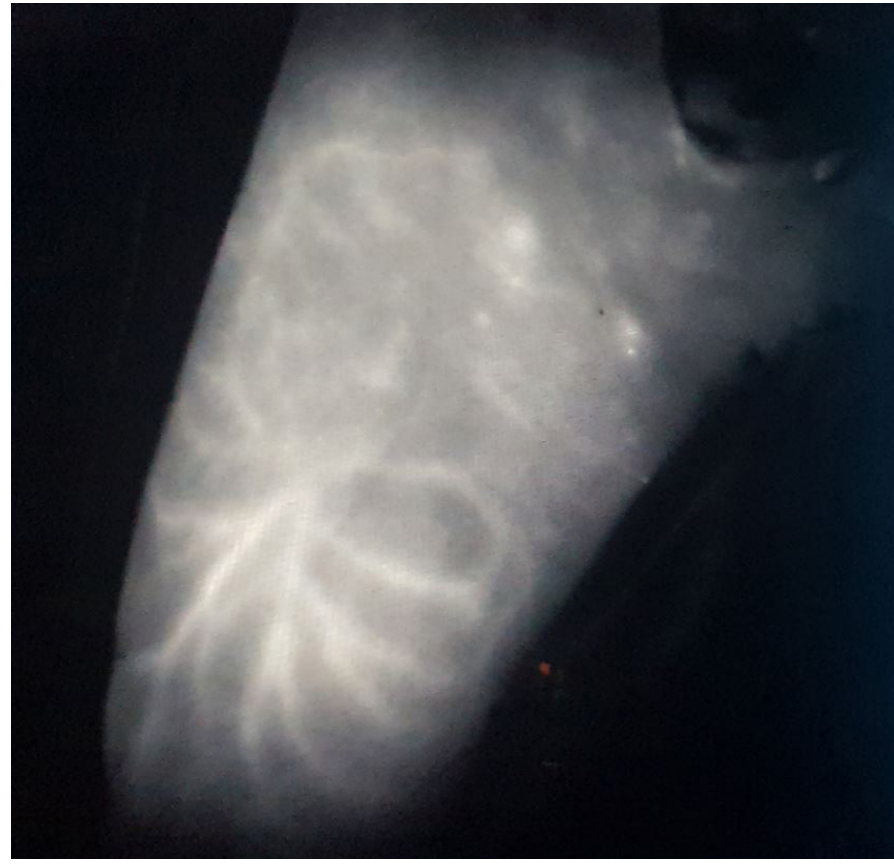

Figure 2. An intraoperative indocyanine green angiography was performed before dissection, and more perforators were identified and marked.

\section{CASE PRESENTATION}

We describe the case of a 70-year-old female patient who had to undergo wide excision of a tumor with squamous cell carcinoma on the left cheek by an otolaryngologist. The reconstruction of the facial defect with a free supraclavicular flap was performed by a plastic surgery team in Sant Pau I Santa Creu
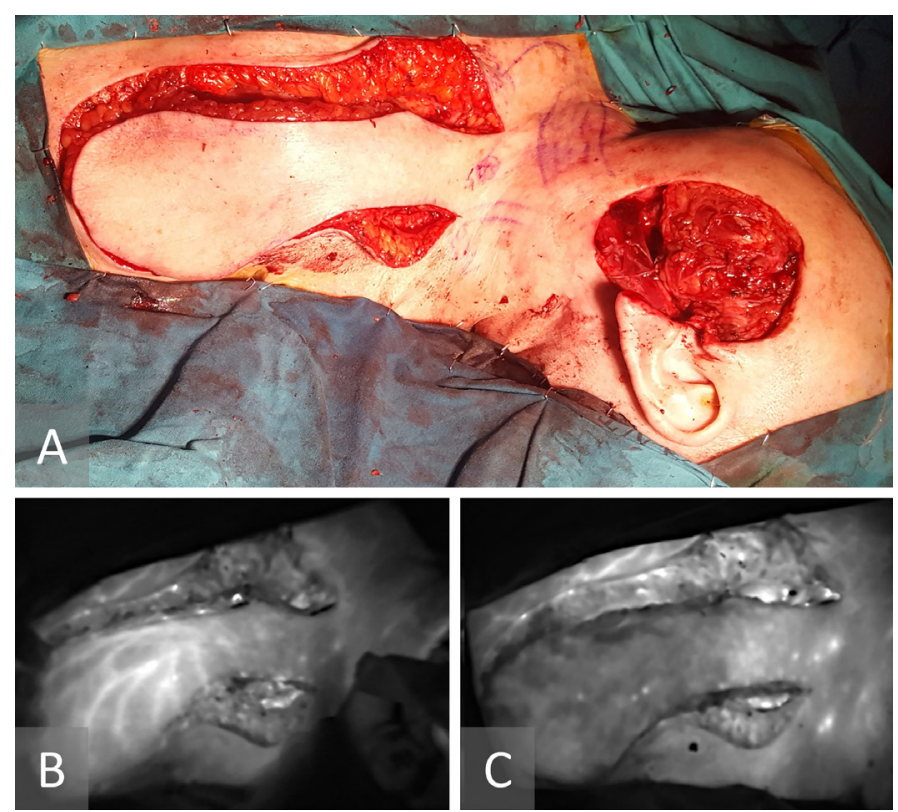

Figure 3. (A) The flap was raised on two pedicles consistent with the results showed by the indocyanine green angiography, one from supraclavicular vessels and the second from subclavicular region. $(B, C)$ Using indocyanine green angiography, both pedicles were sequentially clamped and then released to check the vascularity and perfusion status of the flap. The supraclavicular vessel entered the flap at its proximal third. The infraclavicular pedicle had a bigger caliber and better pulsation than the supraclavicular pedicle but entered the flap in its middle third. hospital in Barcelona, Spain in January 2018.

The wide resection of the tumor resulted in a large soft tissue defect of the size of $8 \times 9 \mathrm{~cm}$. A left supraclavicular perforator flap was planned. The flap pedicle was identified by a handheld Doppler as a single perforator in the triangle outlined between sternocleidomastoid, clavicle and trapezius. The flap borders were marked having a length of $20 \mathrm{~cm}$ from the pedicle and width of $9 \mathrm{~cm}$ at the distal part to match the size of the defect (Figure 1).

An intraoperative indocyanine green angiography was performed before dissection, and more perforators were identified and marked (Figure 2). Dissection started from distal to proximal part of the flap in the subfascial plane.

The flap was raised on two pedicles consistent with the results showed by the indocyanine green angiography, one from supraclavicular vessels and the second from subclavicular region (Figure $3 \mathrm{~A}$ ). Using indocyanine green imaging, both pedicles were sequentially clamped and then released to check the vascularity and perfusion status of the flap. The supraclavicular vessel entered the flap at its proximal third. The infraclavicular pedicle had a bigger caliber and better pulsation than the supraclavicular pedicle but entered the flap in its middle third (Figure 3B-C).

Clinical examination and indocyanine green angiography showed that the subclavicular pedicle was dominant. The arc of rotation of the flap was limited, as was the reach of the pedicled flap. We therefore opted to convert it into a free flap. The proximal quarter of the flap was too narrow and not sufficiently perfused; hence it was discarded (Figure 4A). A branch of the ipsilateral facial artery and the facial vein were prepared as recipient vessels. The flap size was adjusted to match the size of the facial defect $(8 \times 9 \mathrm{~cm})$. It was then inset on the defect, and the infraclavicular pedicle was anastomosed end-toend to the facial vessels (Figure 4B). The donor site was closed at the proximal part and skin grafted at the distal part. The flap survived completely, and the wounds healed up uneventfully five weeks after surgery (Figure 4C).

\section{DISCUSSION}

Radiological mapping of the pedicle and angiosomes of supraclavicular artery flap is useful but complex. Sheriff et al. [3] have compared six imaging modalities for identifying the pedicle and marking the perfusion zones of supraclavicular artery flap. Of these, intraoperative indocyanine green angiography was the most practical and accurate in identifying the vascular anatomy of the superficial vessels in real time, making the mapping of the pedicle and angiosomes reliable [3,17].

However, the ability of indocyanine green angiography in showing the full course of the pedicles and perforators is limited and depends on the amount of adipose tissue subjacent to the skin and the site of emergence of the vessels. As the depth of visualization of blood vessels by indocyanine green angiography is limited to approximately $2 \mathrm{~cm}$ [17], it could show the perforators sites precisely. However, it could not show the pathway of the pedicle deep in the tissue. It also did not show the course of the pedicle above or below the clavicle, and hence there was no change in the initial plan of supraclavicular flap to another type of flap.

In this case, the indocyanine green angiography was able to guide the conversion of the pedicled supraclavicular artery flap to a free supraclavicular flap for reconstruction of the facial defect caused by an unusual course of the dominant pedicle of the flap. The vast majority of articles on the supraclavicular flap in peer-reviewed literature discuss the pedicled design of the flap but there is little discussion about the use of the free flap design.

\section{CONCLUSION}

Intraoperative indocyanine green angiography before and during dissection may be useful in identification of the dominant perforator and pedicle pathways. It helps make a right decision in the ultimate flap design in order to avoid complications which might arise due to anatomic variations. 


\section{CASE REPORT}
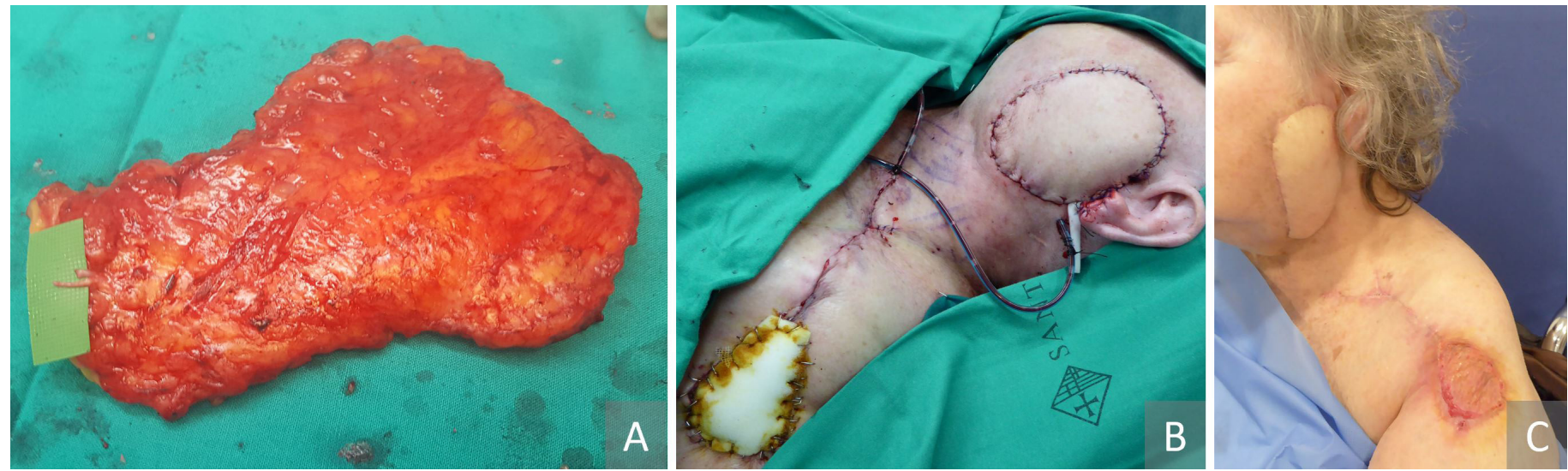

Figure 4. (A) The subclavicular pedicle was dominant and the arc of rotation of the flap was limited. We therefore opted to convert it into a free flap. The proximal quarter of the flap was quite narrow and not sufficiently perfused; hence it was discarded. (B) A branch of the ipsilateral facial artery and the facial vein were prepared as recipient vessels. The flap size was adjusted to match the size of the facial defect $(8 \times 9 \mathrm{~cm})$. It was then inset on the defect, and the infraclavicular pedicle was anastomosed end-to-end to the facial vessels. (C) The donor site was closed at the proximal part and skin grafted at the distal part. The flap survived completely, and the wounds healed up uneventfully five weeks after surgery.

\section{ARTICLE INFORMATION}

*Correspondence: Hemin Sheriff, MD, PhD, Department of Surgery, College of Medicine, University of Sulaimani, Sulaymaniyah, Iraq. Email: hemin.sheriff@univsul.edu.iq

Received: May 10, 2020; Accepted: Sep. 07, 2020; Published: Sep. 02, 2021

DOI: $10.24983 /$ scitemed.imj.2021.00145

Ethics Approval and Consent to Participate: The study is in accordance with the ethical standards of the 1964 Helsinki declaration and its later amendments or comparable ethical standards.

Funding: The study did not receive any specific grant from funding agencies in the public, commercial, or not-for-profit sectors.

Conflict of Interest: The authors report no financial or other conflict of interest relevant to this article, which is the intellectual property of the authors.

Copyright @ 2021 The Author(s). This is an open-access article distributed under the terms of the Creative Commons Attribution 4.0 International License (CC-BY).

\section{REFERENCES}

1. Sheriff H, Garcia CV, Jaber S, et al. Supraclavicular artery island flap: Relation between length and distal end necrosis. Int Microsurg J 2018;2(1):5.

2. Sands TT, Martin JB, Simms E, Henderson MM, Friedlander PL, Chiu ES. Supraclavicular artery island flap innervation: Anatomical studies and clinical implications. J Plast Reconstr Aesthet Surg 2012;65(1):68-71.

3. Sheriff HO, Mahmood KA, Hamawandi N, et al. The Supraclavicular Artery Perforator Flap: A Comparative Study of Imaging Techniques Used in Preoperative Mapping. J Reconstr Microsurg 2018;34(7):499-508.

4. Chiu ES, Liu PH, Friedlander PL. Supraclavicular artery island flap for head and neck oncologic reconstruction: Indications, complications, and outcomes. Plast Reconstr Surg 2009;124(1):115-123.

5. Alves HR, Ishida LC, Ishida LH, et al. A clinical experience of the supraclavicular flap used to reconstruct head and neck defects in late-stage cancer patients. J
Plast Reconstr Aesthet Surg 2012;65(10):1350-1356.

6. Chan JWH, Wong C, Ward K, Saint-Cyr M, Chiu ES. Three- and four-dimensional computed tomographic angiography studies of the supraclavicular artery island flap. Plast Reconstr Surg 2010;125(2):525-531.

7. Kazanjian $\mathrm{VH}$, Converse JM. The surgical treatment of facial injuries, 2 edn. Baltimore: Williams \& Wilkins Company; 1959.

8. Pallua N, Demir E. Postburn head and neck reconstruction in children with the fasciocutaneous supraclavicular artery island flap. Ann Plast Surg 2008;60(3):276282.

9. Pallua N, Machens HG, Rennekampff O, Becker M, Berger A. The fasciocutaneous supraclavicular artery island flap for releasing postburn mentosternal contractures. Plast Reconstr Surg 1997;99(7):1878-1884; discussion 1885-1876.

10. Pallua N, Magnus Noah E. The tunneled supraclavicular island flap: An optimized technique for head and neck reconstruction. Plast Reconstr Surg 2000;105(3):842-851; discussion 852-844.

11. Pallua N, von Heimburg D. Pre-expanded ultra-thin supraclavicular flaps for (full-) face reconstruction with reduced donor-site morbidity and without the need for microsurgery. Plast Reconstr Surg 2005;115(7):1837-1844; discussion 1845-1837.

12. Pallua N, Wolter TP. Moving forwards: The anterior supraclavicular artery perforator (a-SAP) flap: A new pedicled or free perforator flap based on the anterior supraclavicular vessels. J Plast Reconstr Aesthet Surg 2013;66(4):489-496.

13. Alves HRN, de Faria JCM, Busnardo F, Cernea C, Rangel T, Gemperli R. Forehead reconstruction using supraclavicular flap with microsurgical technique: Free flap and a pedicle supercharged flap. JPRAS Open 2017;14:33-38.

14. Cordova A, Pirrello R, D'Arpa S, Jeschke J, Brenner E, Moschella F. Vascular anatomy of the supraclavicular area revisited: Feasibility of the free supraclavicular perforator flap. Plast Reconstr Surg 2008;122(5):1399-1409.

15. Kokot N, Mazhar K, Reder LS, Peng GL, Sinha UK. The supraclavicular artery island flap in head and neck reconstruction: Applications and limitations. JAMA Otolaryngol Head Neck Surg 2013;139(11):1247-1255.

16. Wirtz NE, Khariwala SS. Update on the supraclavicular flap. Curr Opin Otolaryngol Head Neck Surg 2017;25(5):439-444.

17. Liu DZ, Mathes DW, Zenn MR, Neligan PC. The application of indocyanine green fluorescence angiography in plastic surgery.J Reconstr Microsurg 2011;27(6):355364. 